\title{
Brothers in arms: emerging roles of RNA epigenetics in DNA damage repair
}

\author{
Jinwei Zhang* (1)
}

\begin{abstract}
N6-methyladenosine $\left(m^{6} A\right)$ is a widespread posttranscriptional RNA modification that occurs in tRNA, rRNA, snRNA, viral RNAs, and more recently is shown to occur in mRNA in a dynamic, reversible manner. At the epicenter of RNA epigenetics, $\mathrm{m}^{6} \mathrm{~A}$ influences essentially all stages of RNA metabolism. As a result, $\mathrm{m}^{6} \mathrm{~A}$ modulates cell differentiation and pluripotency, cell cycle and tumorigenesis, and several types of stress responses, etc. A recent report by Shi and colleagues uncovers a novel pathway in which $\mathrm{m}^{6} \mathrm{~A}$ RNA, its associated enzymes, and DNA polymerase $\mathrm{k}$ constitute an early-response system that confers cellular resistance to ultraviolet irradiation, separate from the canonical nucleotide excision repair (NER) pathway that normally repairs UV-induced DNA damage.
\end{abstract}

\section{Background}

Among the trio of linear heteropolymers that enable organic life as we know it, RNAs are recognized as the most versatile and self-sufficient. In order to serve its primary directive in the faithful preservation and propagation of genetic information to subsequent generations, DNA assumes a protective, inert duplex structure where sequence information is carefully concealed in is hydrophobic, stacked central axes. Further, the genetic information is maintained in duplicates, in the form of two paired strands, each replete with the 4-bit informational strings. Despite such extraordinary measures to preserve the genetic information, cellular DNA is subjected to a constant onslaught of chemical and environmental insults that create lesions that interfere with its replication, transcription, modification, etc. Depending on the source (ROS, UV, X-rays, Gamma rays, toxins, mutagens, etc.) and type of DNA damage (oxidation, alkylation, hydrolysis, adducts, mismatches, etc.), cells employ a battery of DNA repair pathways to detect and correct the damages. These include base excision repair

\footnotetext{
*Correspondence: jinwei.zhang@nih.gov

Laboratory of Molecular Biology, National Institute of Diabetes

and Digestive and Kidney Diseases, 50 South Drive, Room 4503, Bethesda, MD 20892, USA
}

(BER), nucleotide excision repair (NER; Fig. 1), mismatch repair, etc. that act on single-strand damages, as well as non-homologous end joining (NHEJ), microhomologymediated end joining (MMEJ), and homologous recombination (HR), which repair double-strand breaks (DSBs) [1].

In contrast to DNA, RNA, or "the other nucleic acid", is unburdened from the task of genetic information preservation and thus liberated from the mundane duplex structure of DNA. Instead, it is free to assume single- and double-stranded structures and can fold into tertiary and quaternary structures that rival large proteins in architectural sophistication and complexity. This is exemplified by some of the most important extant cellular machineries such as the ribosome, spliceosome, telomerase, RNase $\mathrm{P}$ and other ribozymes, and riboswitches, etc. Such structural versatility, combined with its short-lived nature, allow RNA to exert an increasingly sophisticated panel of non-inherited, regulatory functions outside of its template role in translation. However, compared to the protein polymers that have gradually taken over most RNA functions since the primordial RNA world, RNA suffers a debilitating lack of chemical diversity on its side chains (4 versus 20). To remedy such limitations, RNA has evolved more than 100 types of chemical elaborations on its nucleobase and ribose moieties. For instance, an average 


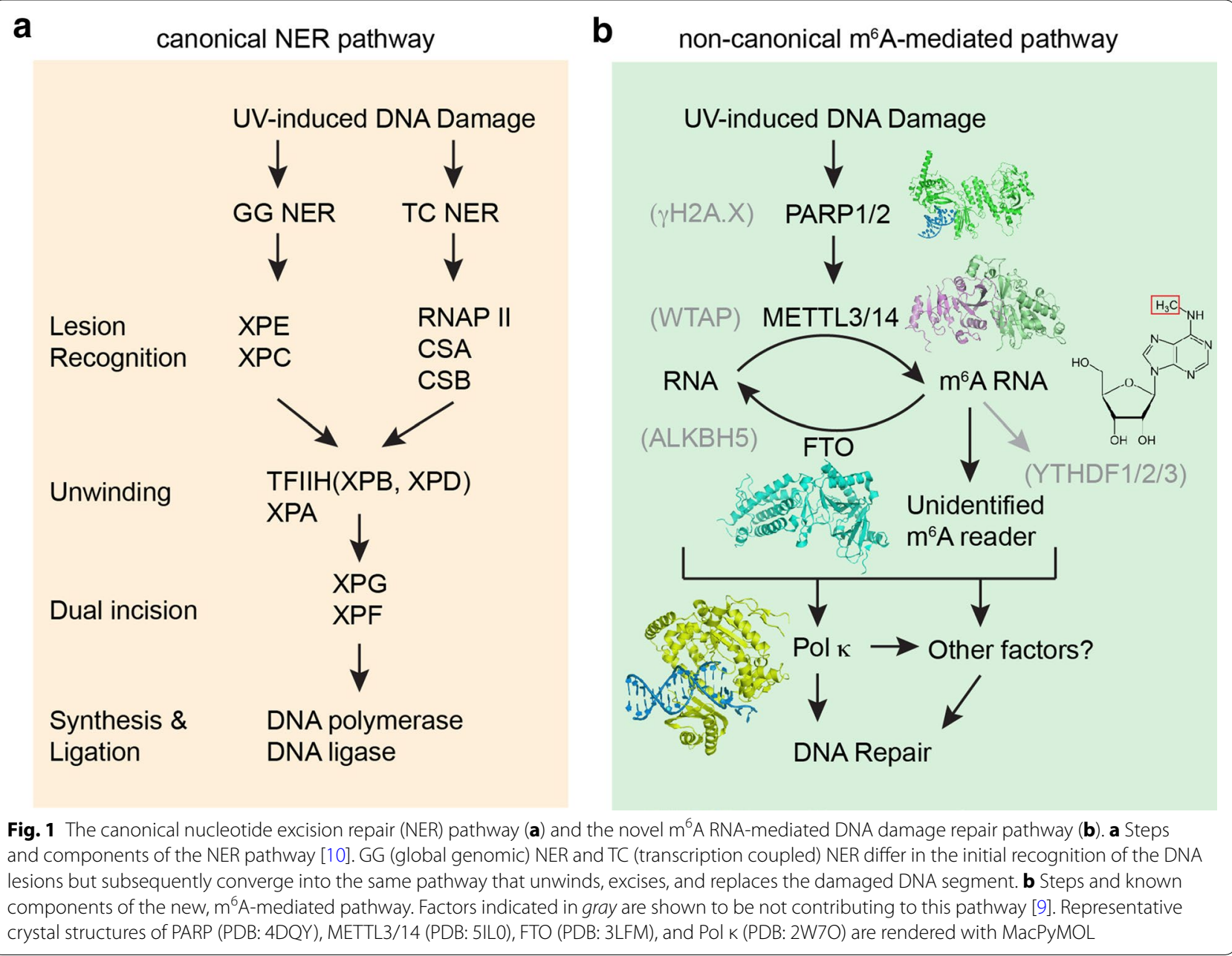

$12 \%$ of nucleotides on tRNA ( $~ 8$ per tRNA molecule) are post-transcriptionally modified. RNA posttranscriptional modifications confer numerous advantages and nuances in modulating RNA structure and function, some of which are further dynamically coupled with the metabolic state of the cell.

\section{A thriving renaissance of RNA epigenetics}

Using genome-wide RNA sequencing methods that can detect and enrich specific modified RNA, it was recently discovered that in addition to tRNAs, rRNAs, snRNAs, etc., that are canonically modified, mRNAs are also elaborated with a number of distinct chemical modifications including N6-methyladenosine $\left(\mathrm{m}^{6} \mathrm{~A}\right)$, N1-methyladenosine $\left(\mathrm{m}^{1} \mathrm{~A}\right)$, pseudouridine $(\psi), 5$-methylcytosine $\left(\mathrm{m}^{5} \mathrm{C}\right)$, and $2^{\prime}$-O-methylation ( $2^{\prime}$-OMe), etc. [2]. These discoveries have ushered in a burgeoning renaissance of RNA modification research, or RNA epigenetics. Among these, $\mathrm{m}^{6} \mathrm{~A}$, or N6-methyladenosine modification, is the most abundant internal modification in eukaryotic mRNA
( 3-5 sites per mRNA) [3, 4]. $\mathrm{m}^{6} \mathrm{~A}$ plays wide-ranging roles in essentially all known steps of RNA metabolism, affecting RNA splicing and processing, nuclear export and localization, translation and stability, etc. These effects are manifest in phenotypic effects on cell differentiation, pluripotency, tumorigenesis, circadian rhythm, etc. $[2,5]$. Further, $\mathrm{m}^{6} \mathrm{~A}$ is involved in several types of stress responses, including heat shock, nitrogen starvation, oxidative stress, hypoxia, etc. $[6,7]$. The deposition of $\mathrm{m}^{6} \mathrm{~A}$ modification can lead to immediate remodeling of RNA secondary and tertiary structures, as $\mathrm{m}^{6} \mathrm{~A}$ weakens duplex formation and stabilizes stacking within single-stranded regions. Such thermodynamic effects not only modulate RNA structure, but also regulate its access by RNA-binding proteins such as HNRNPC, constituting " $\mathrm{m}^{6} \mathrm{~A}$ switches" [8]. Taken together, the dynamic, reversible $\mathrm{m}^{6} \mathrm{~A}$ modification is well suited for fast-acting responses to cellular and environmental stimuli.

Along the emerging theme of $\mathrm{m}^{6} \mathrm{~A}$ acting as early responders of stress response, $\mathrm{Shi}, \mathrm{He}$, and colleagues 
have recently reported a remarkable discovery that $\mathrm{m}^{6} \mathrm{~A}$ in RNA, its associated enzymes Poly-ADP ribose polymerase (PARP), N6-adenosine-methyltransferase heterodimer (METTL3/14), Fat mass and obesity-associated protein (FTO), and DNA polymerase $\mathrm{k}$ (Pol $\mathrm{\kappa}$ ), form a novel, dynamic pathway that launches a rapid response (within $2 \mathrm{~min}$ ) to UV-induced DNA damage [9].

\section{A novel RNA-mediated DNA repair pathway}

Using laser micro-irradiation or global UVC irradiation of U2OS cells and an antibody against $\mathrm{m}^{6} \mathrm{~A}$, Xiang et al., detected rapid, reversible accumulation of $\mathrm{m}^{6} \mathrm{~A}$ RNA at the sites of irradiation [9]. The authors identified the METTL3/METTL14 complex (but not METTL3/WTAP complex) and FTO (but not ALKBH5) as the writer and eraser of the $\mathrm{m}^{6} \mathrm{~A}$ mark at these DNA damage sites (Fig. 1). The factor that operates upstream of the RNA methylation is the early DNA damage responder PARP but not $\gamma \mathrm{H} 2 \mathrm{~A}$.X. Interestingly, this $\mathrm{m}^{6} \mathrm{~A}$ formation is specific for DNA damage induced by UV irradiation and is not triggered by infrared or $\gamma$ irradiation or chemical insults [9].

Enzymatically active METTL3, the methylation writer rapidly recruited to the UV-irradiated DNA damage site, plays a central role in this novel pathway. METTL3 KO cells are characterized by the hindered removal of cyclobutane pyrimidine dimers (CPDs, primary lesions from UV exposure), an inability to recruit downstream effector Pol $\kappa$ to the damage site, significantly delayed re-initiation of nascent transcription after DNA damage, and ultimately drastically reduced cell survival [9]. Remarkably, exogenous over-expression of Pol $\mathrm{k}$ rescues the CPD removal defect, suggesting that rapid Pol $\kappa$ recruitment to the damage site is potentially the purpose of $\mathrm{m}^{6} \mathrm{~A}$ deposition. It remains unknown how exactly $\mathrm{Pol} \kappa$ is recruited to the damage site and whether its translesion synthesis activity is responsible for the $\mathrm{UV}$ resistance conferred by this $\mathrm{m}^{6} \mathrm{~A}$ pathway. Importantly, this $\mathrm{m}^{6} \mathrm{~A}$-mediated DNA damage response is separate from the canonical NER and Rad18/ PCNA pathways, which also recruit Pol $\kappa$ to DNA damage sites, albeit at a much later time (10-30 min; Fig. 1).

\section{Conclusion and perspectives}

This timely work expands the already impressive repertoire of cellular functions $\mathrm{m}^{6} \mathrm{~A}$ plays and makes a surprising connection between $\mathrm{m}^{6} \mathrm{~A}$ RNA biology and DNA repair. Like any other transformative discovery, this work raises more questions that it answers. For example, are specialized transcripts or all nearby RNAs responsible for aiding DNA damage repair? The authors address this question by capturing the GGACU motif used for METTL3 recruitment and demonstrate the enrichment of UV-induced $\mathrm{m}^{6} \mathrm{~A}$ in $5^{\prime}$ untranslated regions (UTR) in a metagene analysis. This finding echoes an earlier analysis of the heat shock response, where increased $\mathrm{m}^{6} \mathrm{~A}$ in $5^{\prime}$ UTR promotes cap-independent translation [7]. Are these marked RNA physically associated with chromatin and are they located near their site of transcription? Do RNA transcripts serve a general protective role for chromatin against damage? Could the $\mathrm{m}^{6} \mathrm{~A}$-marked transcripts play a more direct role besides recruiting METTL3? Besides known protein-binding primary sequence motifs, could the RNA secondary, tertiary, or quaternary structures (which are directly modulated by the deposition and removal of epigenetic marks) contribute to factor recruitment or other functions in this context? Which protein reads the UV-induced $\mathrm{m}^{6} \mathrm{~A}$ deposition and is this protein or the RNA or both that ultimately recruit Pol $\kappa$ ? What is special about Pol $\kappa$ that contributes to its unique recruitment and activity at the damage site, not possessed by other DNA polymerases such as Pol $\delta, \varepsilon, \eta$, ı, etc.?

Nevertheless, what is clear is that this landmark paper leaves us with a fertile area for future research and makes one wonder what other pathways would be next to cross paths with RNA epigenetics and noncoding RNA biology.

\section{Acknowledgements \\ The author apologizes to many colleagues whose work cannot be cited owing to space limitations. Research in the author's laboratory was supported by the Intramural Research Program of National Institute of Diabetes and Digestive and Kidney Diseases (NIDDK), NIH.}

\section{Competing interests}

The author declares no competing interests.

\section{Funding}

This work was supported by the Intramural Research Program of National Institute of Diabetes and Digestive and Kidney Diseases (NIDDK), NIH.

\section{Publisher's Note}

Springer Nature remains neutral with regard to jurisdictional claims in published maps and institutional affiliations.

Received: 21 April 2017 Accepted: 27 April 2017

Published online: 04 May 2017

\section{References}

1. Ciccia A, Elledge SJ. The DNA damage response: making it safe to play with knives. Mol Cell. 2010;40:179-204.

2. Zhao BS, Roundtree IA, He C. Post-transcriptional gene regulation by mRNA modifications. Nat Rev Mol Cell Biol. 2017;18:31-42.

3. Dominissini D, Moshitch-Moshkovitz S, Schwartz S, Salmon-Divon M, Ungar L, Osenberg S, Cesarkas K, Jacob-Hirsch J, Amariglio N, Kupiec M, et al. Topology of the human and mouse m6A RNA methylomes revealed by m6A-seq. Nature. 2012:485:201-6.

4. Meyer KD, Saletore Y, Zumbo P, Elemento O, Mason CE, Jaffrey SR. Comprehensive analysis of mRNA methylation reveals enrichment in $3^{\prime}$ UTRs and near stop codons. Cell. 2012;149:1635-46.

5. Lee M, Kim B, Kim VN. Emerging roles of RNA modification: m6A and U-Tail. Cell. 2014;158:980-7. 
6. Meyer KD, Patil DP, Zhou J, Zinoviev A, Skabkin MA, Elemento O, Pestova TV, Qian SB, Jaffrey SR. 5' UTR m(6)A promotes cap-independent translation. Cell. 2015;163:999-1010.

7. Zhou J, Wan J, Gao X, Zhang X, Jaffrey SR, Qian S-B. Dynamic m(6)A mRNA methylation directs translational control of heat shock response. Nature. 2015;526:591-4

8. Liu N, Dai Q, Zheng G, He C, Parisien M, Pan T. N(6)-methyladenosinedependent RNA structural switches regulate RNA-protein interactions. Nature. 2015;518:560-4
9. Xiang Y, Laurent B, Hsu C-H, Nachtergaele S, Lu Z, Sheng W, Xu C, Chen H, Ouyang J, Wang $S$, et al. RNA m(6)A methylation regulates the ultravioletinduced DNA damage response. Nature. 2017;10:93-576.

10. Yang W. Surviving the sun: repair and bypass of DNA UV lesions. Protein Sci. 2011:20:1781-9.

\section{Submit your next manuscript to BioMed Central and we will help you at every step:}

- We accept pre-submission inquiries

- Our selector tool helps you to find the most relevant journal

- We provide round the clock customer support

- Convenient online submission

- Thorough peer review

- Inclusion in PubMed and all major indexing services

- Maximum visibility for your research

Submit your manuscript at www.biomedcentral com/submit 